\title{
Hyperplasia of Pancreatic Islets Associated with Extrapancreatic Lymphoma and Sarcoma
}

\author{
By William R. Hant and Donin L. Hinerman
}

\begin{abstract}
A preliminary study revealed pancreatic hyperplasia to be present in 29 per cent of 100 consecutive necropsies. Malignant neoplasms coexisted with hyperplasia of islets in 14 ( 48.3 per cent) of the 29 cases. On the basis of the results of this study, the islets of Langerhans in microscopic sections of pancreas from 20 cases of accidental death (normal controls), 10 cases of extrapancreatic lymphoma, and 12 cases of extrapancreatic sarcoma were quantitatively studied. Significant hyperplasia of the islets was present in
\end{abstract}

both categories of neoplastic disease when compared with the islets in the control group. The assessment of hyperplasia of pancreatic islets was neither difficult nor complex when the observer assigned the proper significance to the presence of an increased percentage of large islets. The method for determining hyperplasia of islets and the significance of its presence are discussed. (Metabolism 14: No. 11, November, 11581168,1965 )

$\mathbf{T}$ 1HE ISLETS OF LANGERHANS constitute an extremely plastic endocrine organ. Pathologists and others have recognized marked variations in structure of the islets in numerous pathologic and physiologic conditions. Gomori ${ }^{1}$ stated that the islets responded as a rule by cytologic changes to various acute stimuli while chronic stimulation resulted primarily in alterations in the amount of insular tissue. Hyperplasia of pancreatic islets has been regularly encountered in patients with diabetes mellitus, erythroblastosis fetalis, and in infants born of diabetic mothers. ${ }^{2}$ Lazarus and Volk ${ }^{3}$ listed pancreatic fibrosis, due to carcinoma near the ampulla of Vater, to ligation of the pancreatic ducts, or in severe cases of fibrosis without obstruction, as lesions associated with dense conglomerations of islets resembling "true insular hypertrophy." These authors incriminated chronic hyperglycemia as the probable stimulus for pancreatic islet hyperplasia following the experimental administration of pituitary growth hormone, thyroid hormone, adrenocorticotropic hormone, glucagon and glucocorticosteroids. There have been conflicting reports in the literature as to the effects of Addison's disease on the islets. ${ }^{4 . \bar{I}}$

Hyperplasia of the pancreatic islets frequently has been noted in the reports of necropsies on the patients that had various extrapancreatic malignant neoplasms at The University of Michigan Medical Center. The object of this study was to quantitatively substantiate the existence of this association.

From the Department of Pathology, The University of Michigan, Ann Arbor, Michigan.

Supported by The University of Michigan Cancer Research Institute Project 63, American Cancer Society, Michigan Division.

Received for publication July 9, 1965.

William R. Hakt, M.D.: Rotating Intern, Highland-Alameda County Hospital, Oakland, Calif. (effective July 1, 1965). Donin L. Hinerman, M.D.: Professor of Pathology, The University of Michigan Medical School, Ann Arbor, Mich. 


\section{Materials AND MEthod}

A preliminary study was made to determine the frequency of hyperplasia of paxcreatic islets and the diseases with which it was associated. Microscopic sections of pancreas were cxamined from 100 consecutive necropsies at The University of Michigan Medical Conter, and these were graded on a subjective basis by one observer as to the presence or absence of definite hyperplasia of pancreatic jslets. Upon completion of grading, the clinical and pathologic diagnoses for each case were recorded. Correlations between hyperplasia of islets and coexistent diseases were then made.

The results of this study provided the basis for an objective, quantitative evaluation of the pancreatic islets in patients with malignant neoplasms. Relatively sudclen deaths from gunshot wounds, falls, automobile and motor scooter accidents, and drownings provided it "uormal" control series. Twenty cases were suitable for use. Review of matcrescopic and microscopic findings from postmortem examinations revealed no apparent associated pathologic conditions that might account for alterations in the islets. Any avidence of pancreatic disease or endocrine abnomality diminated the case from the sturly.

Cases of lymphoma and sarcoma were similarly selected as the types of extrapancreatic malignant neoplastic diseases to be studied. Hodgkins disease and reticulum coll sarcoma provided Io cases of lymphoma, while the soft and hard tissue sarcomas (fibrosarcoma, leionyosarcoma, osteogenic sarcoma, rhabdomyosarcoma, chrondrosarcoma, myxofibrosiacomil. and undifferentiated sarcoma) included 12 cases. Any macroscopic or microscopic evidence of neoplastic invasion of the pancreas eliminated the case thus tending to reduce all possible canses of direct pancreatic stimulation. Neither hyperglycemia nor hypoglycomia was recognized in any of the patients who were included in the study. The lower ange limit of 16 ycars wats chosen for cases in the 3 categories to limit ncogenesis of islets as a factor. The rigorous application of these criteria for selcetion of cases of lymphomat and sarcoma was responsible for the small number of cases cven though the review of consecutive necropsy protocols included the period 1929-1963.

Nimmerons methods for determining the volume of pancreatic islet tissue are known. Warren and LaCompte: stated that the most careful quantitative study of the islets of Limgerhans wiss that of Tejningt whose momograph presented vilid criticism of the most popular technies. His data revealed that as the volume of islet tissue increased, the number of islets of all sizes increased. However. the increase in number of islets was relatively more marked in the larger islets than in the sinaller ones. Therefore, Tejning concluded, if in one pancreas a relatively greater number of larger islets was cobserved than in another pancreatic gland. the conchusion wats justified that this wats a sign that the total quantity of islet tissue was greater in the former than in the latter. This conclusion permitted closest attention to be directed to the larger-sized islets as we (hose to do in this study.

Although the number of islets may vary depending on the location within the pancreas, the average size of the islets is the same in all parts of the pancreas. ${ }^{\text {. }}$. Comparison of islct size in different pancreases is, therefore. justificd without concern for the location within the gland.

Since the exocrine and endocrine portions of the pancreas vary in size independently of eacl otluer, $\because, 6$ it was decided not to attempt to define islet volume in terms of percentage of total pancreatic tissue. Merely counting the number of islets in a given are:a also was unsuitable since this procedure required commts in exactly the same portions of the gland and in comparable areas of acinar tissue, i.e., those with the same deares of acimatr atropley and fatty infiltration.

The method used in this study was based on the above concepts. Microseopic sections of pancreas routinely obtained from each selected necropsy wer revicwed. The number if slider per case ranged from 1 to 5 , in most cases 2 slides from different areas of the pancreas were available. The tissue sections were stained with hematoxylin and eosin which provided an adequate differentiation of insular from acinar tissue. A calibritted 
ocular micrometer was utilized to measure the longest diameter of every islet in each available slide of pancreas. Only the measurements of islets greater than $115 \mu$ in diameter, a figure below the average diameter of an islet, ${ }^{4,6}$ were recorded since islets much smaller than this might not be identified. Data from the control series revealed that islets greater than $192 \mu$ in their longest diameter were large. The percentage of large islets in each case was then calculated from the ratio:

$$
\frac{\text { no. of islets greater than } 192 \mu}{\text { no. of islets greater than } 115 \mu} \text { or } \frac{\text { no. of large islets }}{\text { no. of recorded islets }} \text {. }
$$

If this percentage was significantly greater in the pancreatic glands of patients with lymphoma or sarcoma than in the normal controls, the presence of hyperplasia of pancreatic islets was assured.

\section{Results}

Preliminary Study: Definite hyperplasia of pancreatic islets was found in material from 29 of the 100 consecutive necropsies examined in the preliminary control group. In 14 of these 29 cases ( 48.3 per cent) extrapancreatic malignant neoplasms were also present. In the absence of coexisting diabetes mellitus or interstitial pancreatitis, hyperplasia of islets was rarely encountered in patients who died from such chronic illnesses as arteriosclerotic heart disease or chronic renal disease.

Quantitative Study. Table 1 presents the important data relevant to the control group of 20 patients who were victims of accidental death. The percentage of large islets ranged from 13.0 to 46.9 with a mean of 26.9 . An analysis of the data revealed no correlation between the age or weight of the patient, weight of the pancreas, or percentage of large pancreatic islets. Figure 1 is a photomicrograph of a representative pancreatic islet of average size from a case of accidental death.

The group of extrapancreatic lymphomas included 10 patients. The important details and the percentage of large islets in each case are listed in table 2. The range of percentage of large islets was from 15.4 to 59.5 with a mean of 40.1. Statistical analysis of the data from table 1 (normal controls) and table 2 indicated the difference in the percentages of large islets to be significant $(\mathrm{p}<0.005)$. Figure 2 is a photomicrograph illustrating a hyperplastic pancreatic islet from a case of extrapancreatic lymphoma.

Table 3 lists the 12 cases of extrapancreatic sarcomas. The percentage of large islets in this group ranged from 22.3 to 45.7 with a mean of 34.2. Statistical analysis of the data from table 1 (normal controls) and table 3 indicated the difference in the percentages of large islets to be significant $(\mathrm{p}<0.01)$.

The frequency distribution of the percentage of large islets for each of the 3 groups of patients is presented in figure 3 . In 11 of the 20 cases of accidental death in the control group, the large islets comprised greater than 25 per cent of the total number of recorded islets. In 9 of the 10 cases in the extrapancreatic lymphoma group and in 11 of the 12 cases in the extrapan-

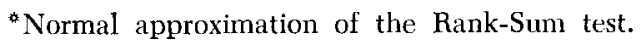


creatic sarcoma group, the large islets comprised greater than 25 per cent of the total number of recorded islets. In 3 of the lymphoma cases ( 30 per cent). the large islets numbered more than one half of the total.

These results indicated an increased amount of insular tissue in selected cases of patients who died with lymphomas and sarcomas. There was hyperplasia of pancreatic islets manifested by a readily apparent increase in the percentage of large islets. Interestingly, pancreases from cases that were excluded from the series because of microscopic invasion of the gland by neoplastic tissue showed similar degrees of hyperplasia of islets.

\section{Discussion}

The association of hyperplasia of pancreatic islets with extrapancreatic lymphomas and sarcomas has been illustrated by this study. Known causes for hyperplasia of tissue including irritational or mechanical factors, compensatory enlargement secondary to loss of actual tissue substance, and hormonal imbalance have been eliminated as much as possible in all cases. Unless one chooses to invoke the etiology "unknown," it is necessary to formulate some hypothesis in order to direct attention to the existence of this association.

The relationship of neoplastic tissue to carbohydrate metabolism has becn intensively studied since the work by Warburg" demonstrated altered metabolic pathways in malignant cells. Neoplastic tissues possess an extraordinarily high rate of anaerobic and aerobic glycolysis. ${ }^{16.11}$ This relatively increased demand for glucose could merely be due to the inordinately high rate of cellular proliferation. Susman ${ }^{19}$ reported 3 cases of malignant disease which had an increase in percentage of islet tissue and 4 additional cases that had islets of increased size. He attributed this to an increase in carbohydrate metabolism which was necessary for the rapid growth of the neoplasm. Less energy per glucose molecule is obtainable from fermentation than from cellular respiratory pathways and respiration appears to be less active in tumors than in most normal tissues." This might also account for the relatively great need for glucose by some neoplasms.

In their review article on the nutrition of tumors. Henderson and LePage ${ }^{11}$ noted that the transplantation of neoplastic tissue (Novikoff hepatoma and Walker carcinoma 256) resulted in reduction of the blood sugar levels of alloxanized rats and that mouse tumors decreased the blood sugar levels of hereditary obese-hyperglycemic mice and alloxan diabetic mice. The sugar content of the tumors was increased under these conditions. Furthermore, depancreatized rats with the Walker tumor had less glycosuria than did the depancreatized control animals. Apparently some neoplastic tissues do not require iusulin for utilization of glucose. Kitt and Griffin ${ }^{11}$ remarked that tumors differ in their sensitivity to insulin and anti-insulin hormones.

Marks and Bishop ${ }^{13}$ reported that selected patients with chronic leukemia, lymphoma and clinically early epithelial neoplasms manifested a decreased glucost tolerance as studied by the intravenous glucose tolerance test. Both the net rate and the fractional rate of disappearance of blood glucose was 


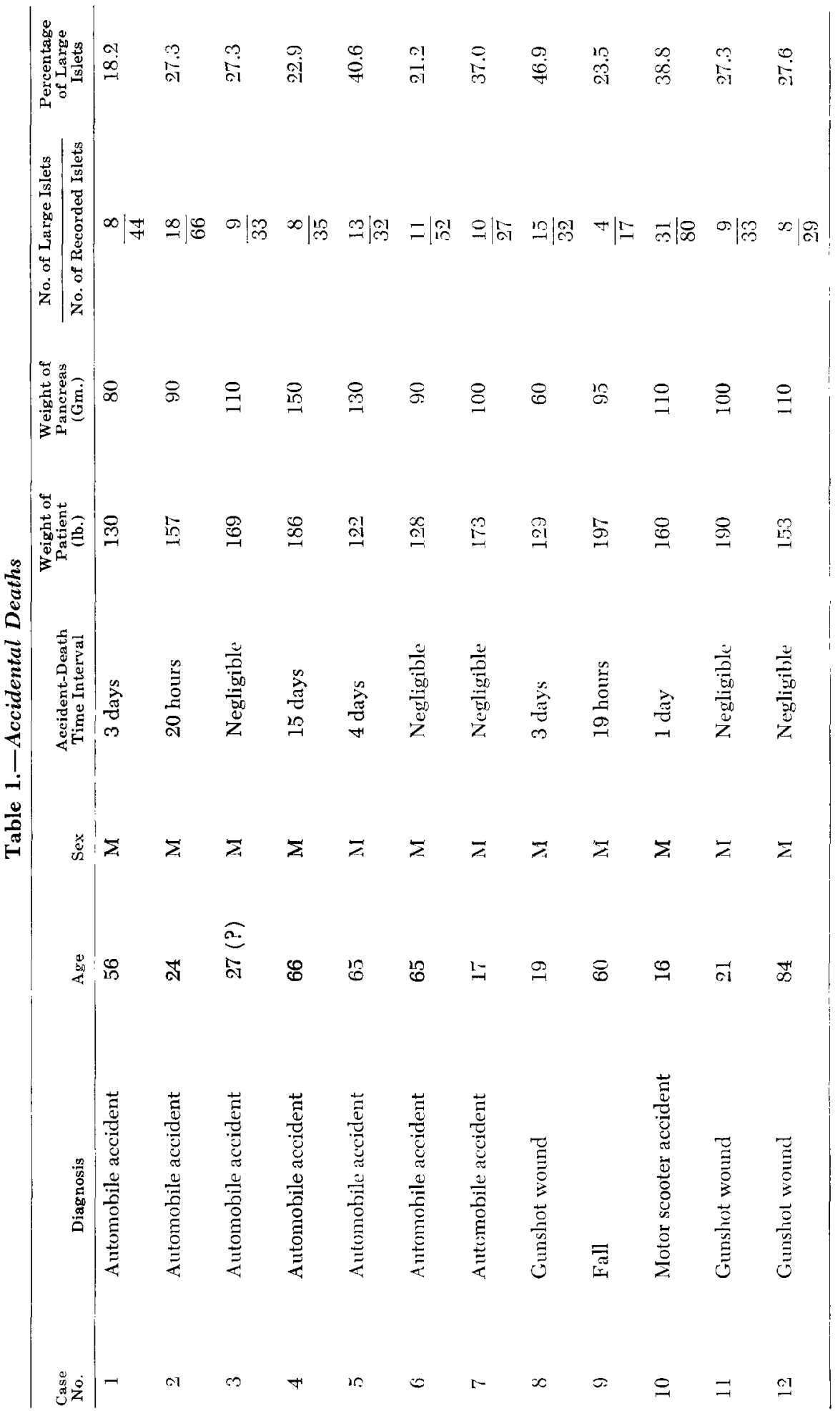




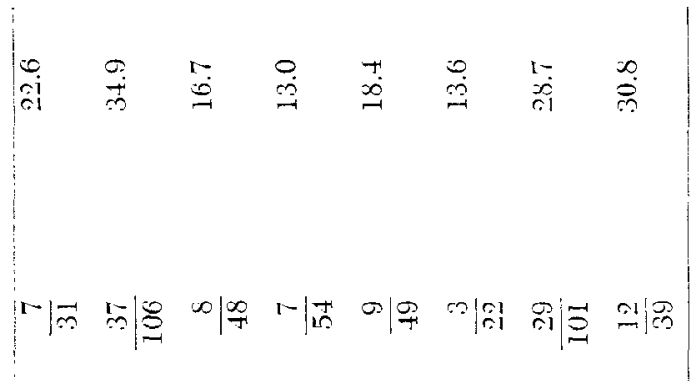

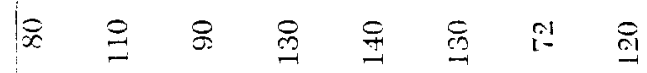

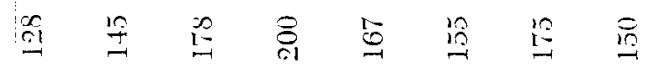

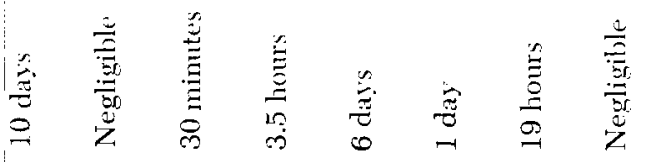

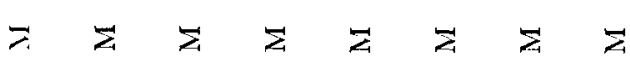

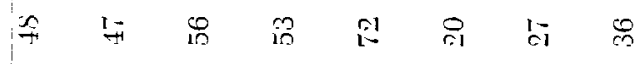

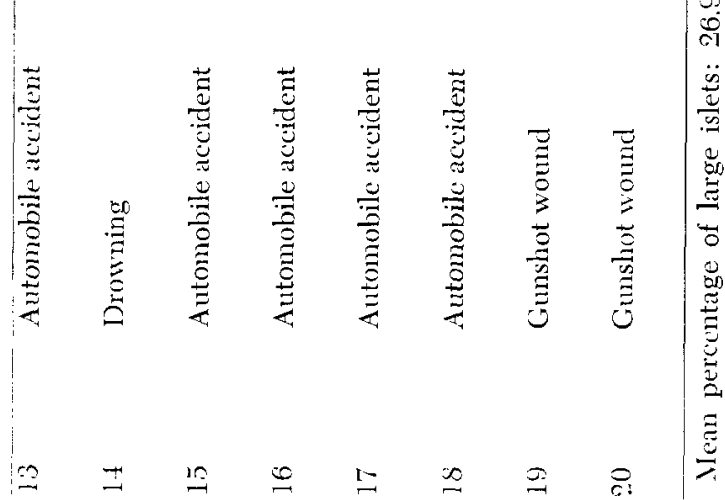


Table 2.-Extrapancreatic Lymphomas

\begin{tabular}{|c|c|c|c|c|c|c|c|}
\hline $\begin{array}{l}\text { Case } \\
\text { No. }\end{array}$ & Diagnosis & Age & Sex & $\begin{array}{l}\text { Weight } \\
\text { of } \\
\text { Patient } \\
\text { (lb.) }\end{array}$ & $\begin{array}{l}\text { Weight } \\
\text { of } \\
\text { Pancreas } \\
\text { (Gm.) }\end{array}$ & $\frac{\text { No. of Large Islets }}{\text { No. of Recorded Islets }}$ & $\begin{array}{c}\text { Per- } \\
\text { contage } \\
\text { of } \\
\text { Isarge } \\
\text { Islets }\end{array}$ \\
\hline 1 & $\begin{array}{l}\text { Reticulum cell } \\
\text { sarcoma }\end{array}$ & 18 & $\mathrm{M}$ & 121 & 70 & $\frac{17}{61}$ & 27.9 \\
\hline 2 & $\begin{array}{l}\text { Reticulum cell } \\
\text { sarcoma }\end{array}$ & 51 & $\mathrm{~F}^{2}$ & 100 & 100 & $\frac{8}{25}$ & 32.0 \\
\hline 3 & Hodgkin's disease & 71 & M & 122 & $?$ & $\frac{10}{18}$ & 55.6 \\
\hline 4 & Hodgkin's disease & 29 & M & 171 & 120 & $\frac{47}{79}$ & 59.5 \\
\hline 5 & Hodgkin's disease & 31 & $\mathbf{M}$ & 180 & 120 & $\frac{29}{74}$ & 39.2 \\
\hline 6 & Hodgkin's disease & 34 & $\mathbf{M}$ & 175 & 130 & $\frac{6}{39}$ & 15.4 \\
\hline 7 & Hodgkin's disease & 61 & $\mathrm{~F}^{2}$ & 135 & 110 & $\frac{36}{107}$ & 33.6 \\
\hline 8 & Hodglkin's discase & 43 & $\mathbf{M}$ & 118 & 70 & $\frac{18}{49}$ & 36.7 \\
\hline 9 & Hodgkin's disease & 44 & $\mathbf{F}$ & 130 & 110 & $\frac{52}{105}$ & 49.5 \\
\hline 10 & Hodgkin's disease & 20 & $\mathbf{M}$ & 140 & 110 & $\frac{15}{29}$ & 51.7 \\
\hline
\end{tabular}

Mean percentage of large islets: 40.1 .

slower. They suggested that the defect in carbohydrate metabolism reflected alterations in the metabolism of host tissue associated with the presence of the neoplastic process and was probably not attributable to the carbohydrate metabolism of the tumor.

Indeed an hypothesis could be formulated with some justification that neoplasms may produce an anti-insulin metabolite capable of inactivating to some extent the peripheral utilization of glucose by the host, thereby diverting glucose to the neoplasm. Since insulin may not be required for glucose utilization by the neoplastic cells, the neoplasm would be teleologically benefited by such circumstances. The diabetic type glucose tolerance test in patients with neoplastic disease could also be a result of such an anti-insulin factor. Such a chain of events could account for the hyperplasia of the pancreatic islets in response to the increased demand by the host tissue for insulinogenesis.

Of paramount importance in substantiating these speculations is the differential staining of the islet cells. This might help to determine the functional activity of these hyperplastic islets. Such a staining procedure, however, requires special technics that could not be performed on the microscopic slides utilized in this study.

The pancreatic islets can be linked to metabolism and tissue growth in yet another fashion. Glucagon and insulin have both been incriminated as factors in growth promotion. Salter and Best ${ }^{14}$ reported that insulin promoted growth 


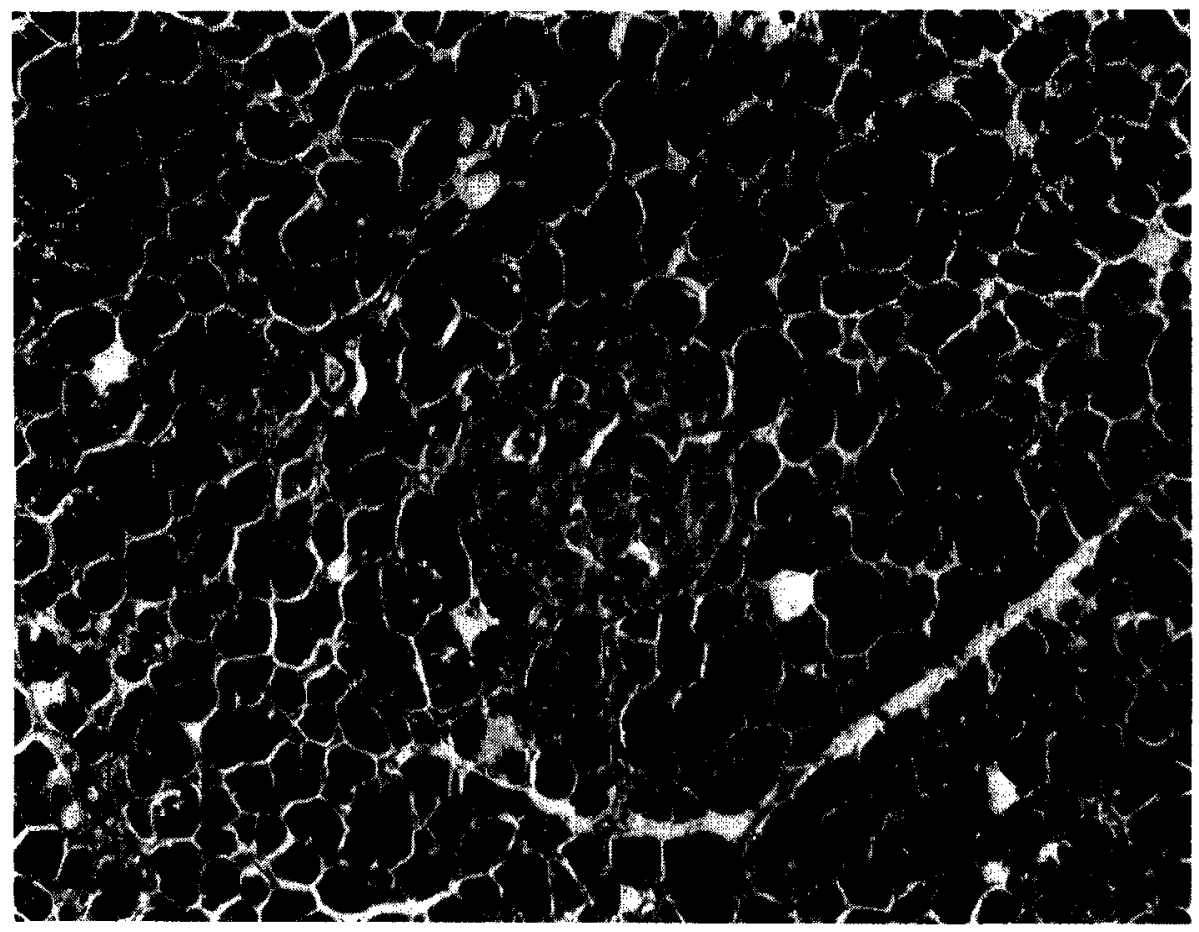

Fig. 1.-(Case 10, table 1.) Islet of Langerhans of average size from a case of accidental death. H. \& E., X145.

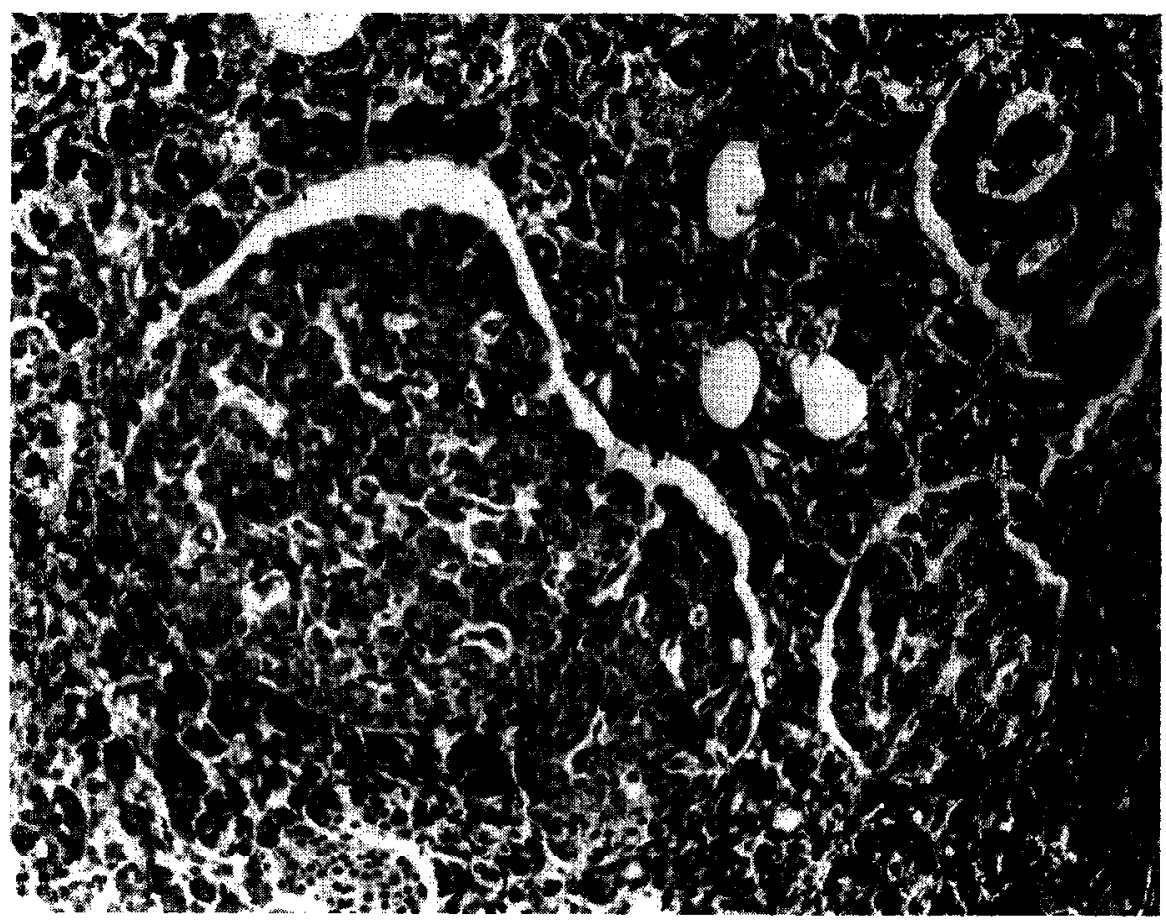

Fig. 2.-(Case 29, table 2.) Hyperplastic islet of Langerhans from a case of extrapancreatic lymphoma. H. \& E., X145. 

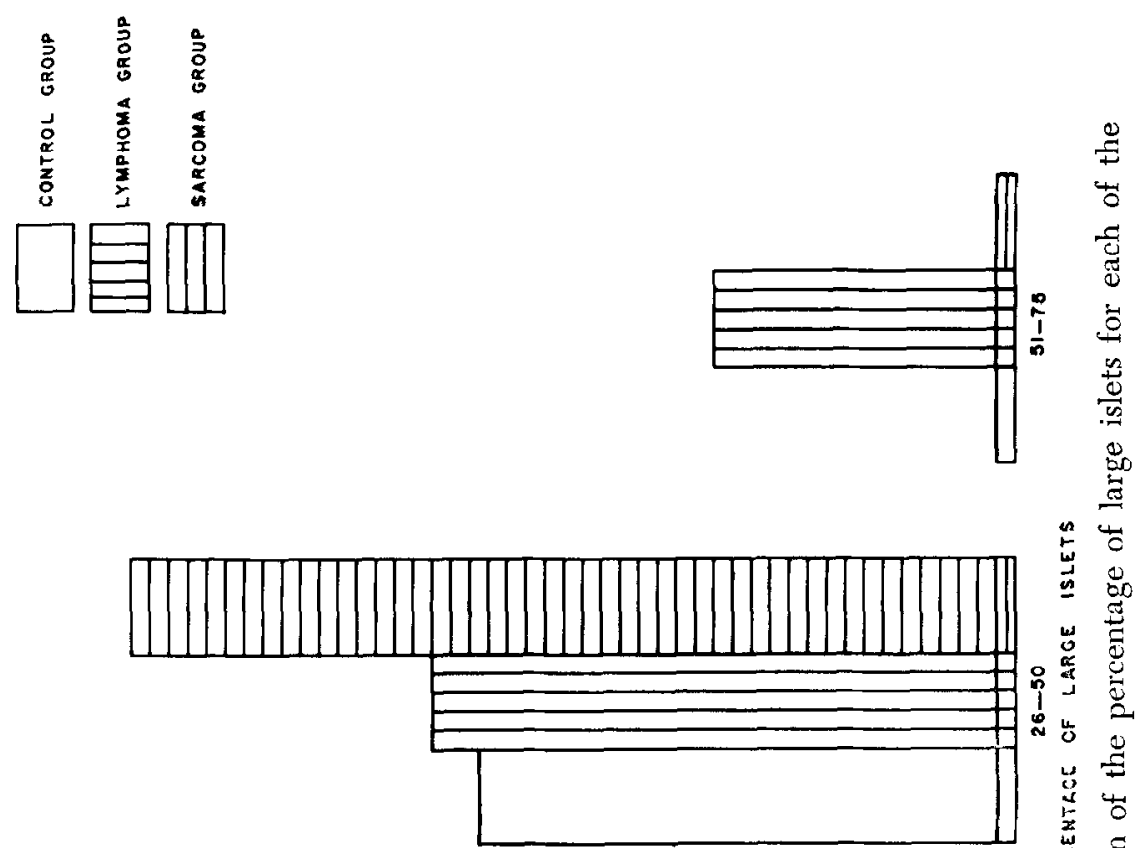

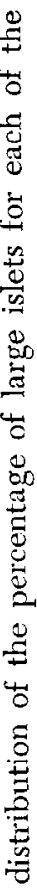

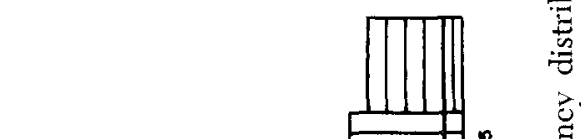

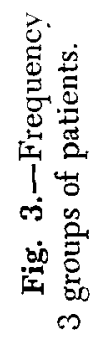

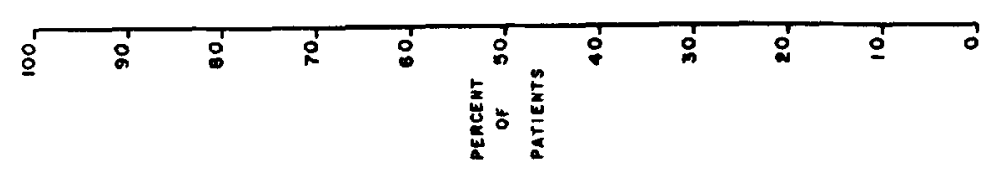


Table 3.-Extrapancreatic Sarcomas

\begin{tabular}{|c|c|c|c|c|c|c|c|}
\hline $\begin{array}{c}\text { Case } \\
\text { No. }\end{array}$ & Diagnosis & Age & Sex & $\begin{array}{l}\text { Weight } \\
\text { of } \\
\text { Patient } \\
\text { (lb.) }\end{array}$ & $\begin{array}{c}\text { Weight } \\
\text { of } \\
\text { Pancreas } \\
\text { (Gm.) }\end{array}$ & $\frac{\text { No. of Lavge 1slets }}{\text { No. of Recorded Islets }}$ & $\begin{array}{c}\text { Per- } \\
\text { centage } \\
\text { of } \\
\text { Large } \\
\text { Islets }\end{array}$ \\
\hline 1 & Osteogenic sarcoma & 36 & $F$ & $1: 31$ & 51) & $\frac{53}{121}$ & 43.4 \\
\hline 3 & Rhabdomyosareoma & 47 & M & 142 & 120 & $\frac{35}{121}$ & $2 \times .9$ \\
\hline 3 & $\begin{array}{l}\text { Undifferentiated } \\
\text { sarcoma }\end{array}$ & 62 & M & $11) 7$ & 71 & $\frac{38}{102}$ & 37.3 \\
\hline 4 & Fibrosa reoma & 29 & Ii & 1014 & 70 & $\frac{30}{92}$ & $: 3.6$ \\
\hline 5 & Chondrosarcoma & 40 & M & 160 & 811 & $\frac{20}{65}$ & 30.8 \\
\hline s) & Chondrosareoma & 42 & $\mathrm{~F}$ & 129 & 6i) & $\frac{18}{5 !}$ & 301.5 \\
\hline 7 & Mysofibrosareoma & $: 36$ & M & $?$ & $?$ & $\frac{31}{13 ! !}$ & 23.3 \\
\hline$x$ & Fibrosa reoma & 56 & M & $1 ! 91$ & 84 & $-\frac{66}{166}$ & 34.4 \\
\hline 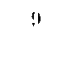 & Leiomyosareoma & 40 & M & 50 & 70 & $\begin{array}{l}10 \\
2 x\end{array}$ & 85.7 \\
\hline 10 & Rhabdomyosarcoma* & 811 & Ir & 87.5 & 50 & $\frac{17}{48}$ & $\because 5.4$ \\
\hline 11 & Chondrosarcoma & 34 & M & $?$ & $?$ & $\frac{8}{29}$ & 27.6 \\
\hline 12 & rhondrosarcoma & 40 & $\mathrm{~F}$ & 130 & 65 & $\frac{64}{140}$ & 45.7 \\
\hline
\end{tabular}

Mean percentage of large islets: 34.2 .

* Patient also had an adenocarcinoma of cecum resecterl 2 years prior to death (no residual carcinoma at necropsy).

in hypophysectomized rats. Cavallero ${ }^{15}$ considered glucagon also to be all active growth-stimulating factor capable of inducing "true growth" in embryonic life as well as in pituitary dwarfism. Perhaps these pancreatic endocrine hormones also stimulate the growth of neoplastic tissue.

Case reports of patients manifesting hypoglycemia and extrapancreatic ne'oplasms ${ }^{16}$ are numerous in the literature. Histologic evidence of increased islet cell activity has not yet been observed in such patients. As this study illustrates. it is important to realize that hyperplasia of islets may coexist with extrapancreatic neoplasms in patients who do not have hypoglycemia. Recognition of this will prove valuable in future studies of the pancreas in patients with the hypoglycemia-neoplasia association.

Whatever the implications of the association between hyperplasia of islets and extrapancreatic neoplasia may be, the necd for more careful morphologic, 
biochemical and immunologic correlations in patients with neoplastic disease has been demonstrated.

\section{ACKNOWLEDGMENT}

We wish to thank Dr. C. J. Lafler for his devoted contributions of time and energy to this study, and Dr. Stephan Fajans for his valuable assistance.

\section{REFERENCES}

1. Gomori. G.: Pathology of the pancreatic islets. Arch. Path. 36:217-232, 1943.

2. Warren. S. and Le Compte, P. M.: The Pathology of Diabetes Mellitus. Philadelphia, Lea \& Febiger, 1952, 336 pp.

3. Lazarus, S. S., and Volk, B. W.: The Pancreas in Human and Experimental Diabetes. New York \& London, Grune \& Stratton, 1962. 279 pp.

4. Hinerman, D. L.: Cytology of hyperplastic pancreatic islets in Addison's disease. Arch. Path. 51:539-547, 1951.

5. Sloper, J. C.: Small islet adenomati in Addison's disease. Arch. Path. 58: 294-303, 1954.

6. Tejning, S.: Dietary factors and quantitative morphology of islets of Langerhans: Experimental study of influence of caloric composition of diet on islets of Langerhans and analysis of relation between volume of islet tissue and number of islets in rat. Acta med. Scandinav., suppl. 198. pp. 1-154, 1947.

7. Cardell, B. S.: Hypertrophy and hyperplasia of the pancreatic islets in newborn infants. J. Path. \& Bact. 66: 335-346, 1953.

8. Idaguesse, E.: Cited by Lazarus. S. S., and Volk, B. W., ${ }^{3}$ p. 26.

9. Warburg, O.: The metabolism of car- cinoma cells. J. Cancer Res. 9:148$163,1925$.

10. Henderson, F. J., and Le Page, G. A.: The nutrition of tumors: a review. Cancer Res. 19:887-902, 1959.

11. Kit, S., and Griffin, A, C.: Cellular metabolism and cancer: a review. Cancer Res. 28:621-656, 1958.

12. Susman. W.: Quantitative variations of pancreatic islet tissue in a mixed series of cases. J. Clin. Endocrinol. 2: 97-106, 1942.

13. Marks. P. A.. and Bishop. J. S.: The ghlucose metabolism of patients with malignant disease and of normal subjects as studied by means of an intravenous glucose tolerance test. J. Clin. Invest. 36:245-264, 1957.

14. Salter. J. M., and Best, C. H.: Insulin as growth hormone. Brit. M. J. 2:353356, 1953.

15. Cavallero, C.: Pancreatic islets and growth. In Wolstenholme. G. E. W., and O'Connor, C. M. (eds.): Internal Secretions of the Pancreas. Ciba Foundation Colloquia on Endocrinology. Boston, Little, Brown \& Co.. 1956. pp. 266-279.

16. Silverstein, M. N., Watkins, K. G., and Bahn. R. C.: Hypoglycemia associated with neoplasia. Amer. J. Med. 36: 415-423. 1964 . 